ISMC 2021

$16^{\text {th }}$ International Strategic Management Conference

\title{
SPECIFICS OF RESERCH AND DEVELOPMENT PROJECT MANAGEMENT - CASE STUDY OF NANOBIO PROJECT
}

\author{
Kristyna Koucka (a), Jana Kostalova (b)*, Simonu Munzarova (c), Alexandra Zahorska (d) \\ *Corresponding author \\ (a) University of Pardubice, Studentska 95, Pardubice, Czech Republic, kouckakristyna@gmail.com \\ (b) University of Pardubice, Studentska 95, Pardubice, Czech Republic, jana.kostalova@upce.cz \\ (c) University of Pardubice, Studentska 95, Pardubice, Czech Republic, simona.munzarova@upce.cz \\ (d) University of Pardubice, Studentska 95, Pardubice, Czech Republic, alexandra.zahorska@student.upce.cz
}

\begin{abstract}
In the current strong pressure of the competitive environment, companies are forced to monitor scientific and technical changes that could affect the business areas in which they operate. There is a dynamic increase in innovation, which leads to higher demands on investment in research and development due to a more flexible response to change. The area of research and development is very important for fulfilling the company's strategy and research and development is becoming increasingly important for maintaining competitiveness and in terms of sustainability. Changes in research and development are implemented in the form of projects, which are specific to a high degree of uncertainty and risk, which limits the possibilities of using traditional waterfall project management procedures. Research and development projects take many forms depending on the nature of the research, the focus of the innovation and the field of implementation. The article focuses on the specifics of research and development projects, assessment of the possibilities of using methods of waterfall and agile project management, or their combinations and evaluation of how to manage the basic parameters of research and development projects. Subsequently, in the form of a case study, it assesses the form of application of project management methods and tools to a specific research and development project. In general, the article provides recommendations for the management of research and development projects and the proposal of appropriate procedures for unplanned activities in the project with the help of combinations of waterfall project management and agile project management.
\end{abstract}

2357-1330 @ 2021 Published by European Publisher.

Keywords: Agile project management, NANOBIO, project management, research and development project management, waterfall project management 


\section{Introduction}

Over time, research and development (R\&D) has become increasingly important for maintaining competitiveness, as well as for sustainability (Hernandez-Gonzalez et al., 2014). Changes in R\&D are addressed in the form of projects that are very specific, as they are accompanied by a high degree of uncertainty, risk, and limited possibility of detailed planning. There is no uniform approach defined for $R \& D$ projects due to the ambiguous classification of these projects, as this is an unexplored area and various authors recommend using different approaches to managing these projects. Larsen (2005) characterized area of $R \& D$ as a desire for little structure, a need to experiment without a lot of oversight, and an interest in exploring interesting and perhaps valuable side trails. Project management (PM) theory generally offers a number of approaches to managing R\&D projects: modification of waterfall PM in accordance with R\&D structure (Larsen, 2005), agile PM (Ko et al., 2016) their various forms of combinations in the form of hybrid PM (Doležal, 2021). The aim of the article is to focus on the specifics of R\&D PM and based on the assessment of a specific project in the form of a case study, define general recommendations for managing R\&D projects and propose appropriate procedures for unplanned activities in the project to achieve the desired output.

\section{Literature Review}

Science, research, development and innovation are interlinked activities that lead to a positive impact on economic, social and sustainable development (Hernandez-Gonzalez et al., 2014). Research is often referred to as a continuous process of research in order to interpret, discover or rework facts. Development means a systematic process of change from the current state to the new one. R\&D can be divided into basic and applied research. Basic research is theoretical or experimental activities carried out in order to gain new knowledge about basic phenomena or observed facts that do not lead to direct commercial use. Applied research means industrial research or experimental development, which is focused on gaining new knowledge and is led to a practical goal. (Reulen, 2002) R\&D activities are focused on the fulfillment of a certain goal, the fulfillment of which takes place in a time- and resourcelimited space and thus meet the characteristics of the project. For effective management of R\&D projects, it is appropriate to use PM methods and tools (Č́slavová, 2018). Roussel et al. (1991) and Rothwell (1994) described the development of R\&D, the current one considers the third generation, characterized as a holistic approach, market oriented, based on networking and with flexible approach to innovation processes.

\subsection{Innovation management strategy in $R \& D$}

$R \& D$ is part of the strategic goals of management and its performance is one of the indicators of the company's competitiveness. The company is forced to monitor innovative activities in the market, and especially their innovation strategy. Companies are dependent on the successful completion of innovation and the development of new products or modifications to existing ones, also for the purpose of sustainability, which is considered a key factor in many industries. Businesses often set up temporary organizations to provide R\&D, interconnecting through joint ventures, networking, while remaining 
separate and independent economic entities. This allows companies to share their knowledge and technology and spread R\&D costs among themselves (Barbosa et al., 2020). Iamandi et al. (2014) states that companies show higher innovation activities in the case of joint R\&D. Barbosa et al. (2020) argues that in such projects, there may also be problems arising from differences in approach in terms of practices, goals and expectations. Especially in the case of cooperation between science-oriented partners and market-oriented partners. On the contrary, Mikulskiene (2014) highlights the benefits of this collaboration, as private sector companies can spread the risk posed by $R \& D$ projects and public sector companies can benefit from increased performance and awareness among private companies, researchers and bridge the gap between theory and practice.

\subsection{Specifics of R\&D PM}

If the contracting authority is able to specify in detail the R\&D procedure and its output in advance, waterfall PM is approached. Agile PM is approached if the contracting authority is not able to specify in detail the research process and the output of the entire project and is delivered in parts that may change throughout the project (Čáslavová, 2018). Since the field of R\&D is still rather unexplored and it is not possible to determine which approach is correct, in any case it is crucial to achieve high success in the implementation of these projects (Doskočil, et al., 2016). Macháčková (2014) recommends rather agile PM for the management of $R \& D$ projects, as they often do not know either the scope of input requirements or, conversely, the procedure or technology by which the output should be achieved. Agile PM achieves the creation of a certain intermediate product, which already has a price for the customer and there is a continuous refinement of requirements and verification of the correct direction of $R \& D$ (see Figure 1). Waterfall PM often increases resources in this area and exceeds the time schedule (Macháčková, 2014). This is also confirmed by Spalek (2016), who states that due to the high risk and uncertainty of R\&D projects, the waterfall PM waterfall is unsatisfactory.

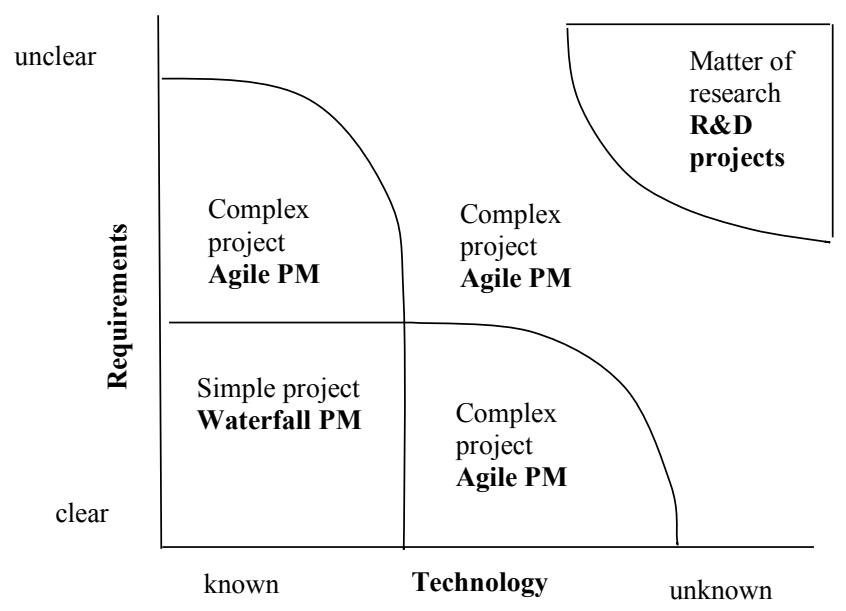

Figure 1. The types of projects and the type of PM (Macháčková, 2014)

Kuchta and Skowron (2016) divides projects into a matrix according to objectives / outputs and methods, which distinguish four types of projects, see Table 1 . 
Table 1. Matrix of project goals and methods (Kuchta \& Skowron, 2016)

\begin{tabular}{ccccc}
\hline Types of projects & Type 1 & Type 2 & Type 3 & Type 4 \\
\hline Well-defined project goal / output & YES & YES & NO & NO \\
Well-defined methods & YES & NO & YES & NO \\
\hline
\end{tabular}

Type 1 represents engineering or construction projects, Type 2 product development projects, Type 3 software development projects and Type 4 R\&D projects. Kuchta and Skowron (2016) also admits ambiguity in the classification of R\&D projects and can therefore be classified as Type 2 or Type 3 projects, as $R \& D$ projects may have a defined output objective or a defined method to achieve the project objectives, but especially in basic research. it can be Type 4.

Dave Snowden defined a framework for Cynefin decision support based on which projects can be divided into four areas (see Figure 2). It is more appropriate to use a different approach to PM for each area (Kempermann, 2017; Puik \& Ceglarek, 2015).

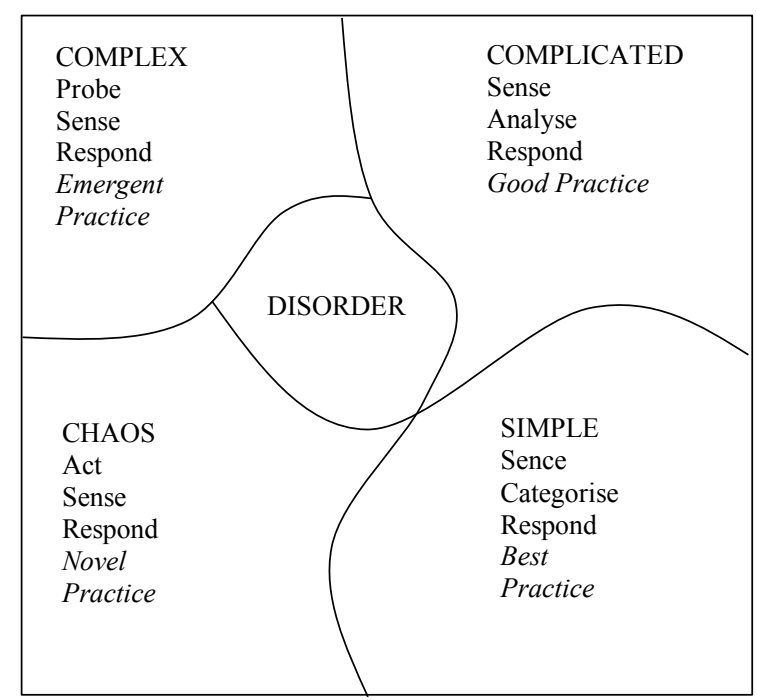

Figure 2. Framework for Cynefin decision (Puik \& Ceglarek, 2015; Kempermann, 2017)

The first area is the so-called simple domain, in which a large number of changes is not expected, and in which there is not a large risk of uncertainty of the result and it is clearly possible to manage it by waterfall PM. The second area is a complicated domain, where small changes can be expected and the result is more uncertain than a simple domain. However, thanks to expert estimates, the project can be planned in advance and waterfall PM is suitable for their management. The third area is the complex domain, in which a lot of changes take place during the project and the output requirements change. These projects are based on the creation of an experiment or prototype, then feedback from customers is created and then the direction of the project is adjusted. The use of agile PM is more appropriate for this domain. The fourth area is the chaos domain, it is a very chaotic and dynamic story. In these cases, there is no room and time for analysis or creation of experiments. The fifth domain is the so-called disorder, where no suitable management method is defined (Kempermann, 2017; Puik \& Ceglarek, 2015). PM can be approached purely traditional - waterfall, agile PM or we can approach a combination of both approaches within one project, which is one of the latest trends in PM (McGrath \& Kostalova, 2020). 
This approach appropriately combines traditional and agile PM according to the individual needs of each project. Hybridization of both approaches can occur (Doležal, 2021):

- In time,

- In detail,

- In outputs.

A combination "in time" is a management approach in which one approach is applied first and then the other over time. It can be an agile approach at the beginning of the project, where individual sprints are used to create, develop and specify assignments and requirements. After its approval, it can move to the waterfall PM, where, for example, the actual production of a specific product takes place. A hybrid approach "in detail" means an approach in which the waterfall approach takes place in the upper parts of the Work Breakdown Structure (WBS), in general elements. In the lower parts of the WBS, in the very detail of the project, when the details are not known and planable in advance, agile management is approached, where the product of this management is the lower part of the WBS. The division "in outputs" is again based on the creation of WBS, where we manage the individual outputs of the project in different ways on the basis of what specific outputs are involved and what is the most effective way to achieve them (Doležal, 2021). Currently, the diversity of R\&D projects is an issue in selecting the appropriate methodology for specific types of $\mathrm{R} \& \mathrm{D}$ projects. When managing projects, it is necessary to consider the scope of the project, the frequency of changes, the level of defining project outputs and also the research and technological uncertainty, i.e. technological novelty of research methods and the project output itself (Kuchta \& Skowron, 2016). Many procedures are only applicable to the private sector, as projects in the public sector are often bound by legislative requirements, especially externally funded projects. At present, moreover, projects in public space, especially at the European level, are associated with a limitation that indicates the level of Technology Readiness Level (TRL) the project can be implemented, TRL indicates the degree of implementation of R\&D activities and exerts pressure to direct research from theoretical knowledge to application research and the commercialization of outputs supported by R\&D projects. This approach increases the efficiency of funds invested in R\&D, as basic research projects already require the definition of the final results and outputs of this research.

In the individual phases of the project life cycle, it is desirable to use appropriate methods and tools of PM (Kostalova \& Tetrevova, 2016). In the pre-project phase, decisions are made on the feasibility and implementation of the project. For R\&D projects, the ability to deliver the required output is addressed in terms of know-how and experience with similar projects. For externally funded R\&D projects, the charter may be replaced by a project proposal or a grant agreement. However, it often happens that the budget for $\mathrm{R} \& \mathrm{D}$ projects is incorrectly set, primarily due to the high level of risk and low experience of the project team (Č́slavová, 2018). Vincente-Oliva et al. (2015) consider it important to build on Lessons Learned past projects and draw key information based on experience. In the project phase within planning, it is important to provide transparent information and manage the risk plan (Č́slavová, 2018). In the case of R\&D projects, stakeholders' expectations regarding project output are much higher than for other types of projects, however, the risk of failure is very high. The number of failed projects is estimated at around 20\%. Projects that exceed budget, time or reduce scope during the course are around $40 \%$. For these reasons, Spalek (2016) considers risk management to be a key area of 
PM, and considers the universal methods of risk and opportunity management used in waterfall PM to be insufficient. The goal of managing the risks and opportunities of R\&D projects should be to minimize negative and maximize positive effects (Spalek, 2016). The WBS also plays an important role, thanks to which the whole project is planned into several levels of tasks and responsibilities for them (Čáslavová, 2018). For individual types of projects, we can also characterize the difference in Organization Breakdown Structure (OBS), the breakdown of the organization structure or organizational chart, which shows a hierarchical division in the company structure and individual relationships between them, OBS is based on the WBS (see Table 2). Product Breakdown Structure (PBS) is used for hierarchical breakdown of product outputs, which should be the goal of the project (Kuchta \& Skowron, 2016) (see Table 2).

Table 2. Structure breakdown for different types of projects (Kuchta \& Skowron, 2016)

\begin{tabular}{lcccc}
\hline \multirow{2}{*}{$\begin{array}{c}\text { Hierarchic } \\
\text { structure }\end{array}$} & Type 1 & Type 2 & Type 3 & Type 4 \\
\cline { 2 - 4 } OBS & Well-defined & Well-defined & Well-defined & Well-defined \\
WBS & Well-defined & $\begin{array}{c}\text { Not defined at all or } \\
\text { partially }\end{array}$ & $\begin{array}{c}\text { Well or partially } \\
\text { defined }\end{array}$ & $\begin{array}{c}\text { Not defined at all or } \\
\text { partially }\end{array}$ \\
& & Well defined at all or & Not defined at all or \\
PBS & Well-defined & Well-defined & partially & partially \\
\hline
\end{tabular}

Completion of R\&D projects should be accompanied by the conclusion of process documentation, from the logical framework matrix and charter to the signing of the acceptance protocol and the conclusion of relevant product documentation such as technical documentation, warranty conditions or instructions for use, which plays an important role in applied research projects. In the post-project phase, it is recommended to apply Lessons Learned to R\&D projects, to gather experience about problems that occurred during the project and how they were solved (Čáslavová, 2018).

\subsection{Management of basic parameters of $R \& D$ projects}

For scope and quality management, it is important to identify measurable goals to be achieved in R\&D projects. However, these principles are sometimes criticized for their excessive formality and lack of flexibility. In addition to the traditional three imperatives, Barbosa et al. (2021) indicates the number of patents, scientific publications, new products or processes as an indicator of the project's success. Evaluation based on scientific publications can only be used in public institutions. It is advisable to involve members of the project team who will perform the activity in the creation of the time schedule and estimation of the time intensity of activities. According to Čáslavová (2018), however, it happens that due to the high degree of uncertainty, employees overestimate the necessary time. A similar situation puts it in the budget estimate. Mikulskienè (2014) states that the most challenging task of a project manager is to manage team dynamics and dissatisfaction, which may occur due to different expectations of individual team members. It has been shown that the performance of $R \& D$ project teams is higher in teams where informal relationships predominate (Mikulskiené, 2014). If we have a fixed project team structure, we can reap the benefits of shared knowledge and knowledge integration through team trust and cohesion, but this can lead to a negative impact in the form of a lack of creativity in innovative ideas. However, if we have a temporary project structure created, where team members change within the project, more 
flexibility and dynamism can be achieved. Conversely, if changes occur in project teams too often, it can lead to poorer performance of the entire project team. The results say that the relationship between a fixed project team and the success of the project has the shape of an inverted U-curve, when after exceeding the optimal value there are negative effects on the innovation of projects (Buengeler et al., 2020).

Risk management is very often neglected in $R \& D$ projects, especially in internally funded projects. The presence of high R\&D uncertainty leads to higher risks that can lead to project failure (Kasap et al., 2007). If the analysis and solution of possible risks of the project at an early stage of development is performed, the given decisions may become inadequate over time and it is necessary to update them due to dynamic change in technology but also market environment (Taraba et al., 2016). For these reasons, emphasis is placed on the flexibility of R\&D management, which, however, can bring higher cost requirements. An important step should be to identify critical risks that can significantly affect the success of the project or lead to its failure. According to Wang and Yang (2012), we can divide the risks into:

- strategic risks (e.g., business model, number of patients),

- development risks (e.g., safety, efficiency),

- business risks (e.g., competitive advantage, product value),

- regulatory risk.

Dividing into several categories can help project managers better identify, monitor and control critical risks. Internal and external communication is another important parameter for the management of R\&D projects. In different companies or research organizations, communication can take place completely differently. Informal communication can contribute to team integration and trust between individual members. Formal communication should be set up to share general information about the project (Barbosa et al., 2021). Communication between stakeholders can be complicated in R\&D projects if it is a potentially controversial issue. Conflicting interests of individual parties can significantly affect the entire course of the project. An important aspect of stakeholder management is their importance, position and interests (Elias, 2016). From the perspective of companies, R\&D projects are an uncertain investment, and therefore it is necessary to pay increased attention when selecting them. There are many different approaches that try to come up with a solution that would help in making decisions when choosing the implementation of projects and help reduce the risk of uncertainty. Recently, artificial intelligence has also been used to evaluate projects, such as the neural network for projects that have been pre-divided according to a decision tree algorithm, where individual classes have been analyzed by gray relational analysis (Lee et al., 2020), or virtual reality for multi-R\&D PM (Ver, 2018). Schuhmacher et al. (2021) states in its work that currently $37 \%$ of PM processes can be performed using machine learning and other artificial intelligence technologies, and up to $80 \%$ of a project manager's work can be performed using artificial intelligence in 2030. At present, machine learning can be used to analyze trends, classify risks or analyze remote data. The involvement of artificial intelligence in the PM process will reduce the cost of financial and human resources. However, companies have to make high initial investments in artificial intelligence technologies and professionals, such as data scientists. 


\section{Research Method and Results}

\subsection{Research Method}

The aim of the article is to present in the form of a case study an analysis of R\&D PM focusing on the specifics of this type of project and designing appropriate management procedures usable in planning activities and project implementation. The NANOBIO project was chosen as a case study, the aim of which is to create a multidisciplinary center of research institutes focused on the development of new nanomaterials, their surface modification and biofunctionalization, and testing the impact of nanomaterials on the human body. This project is implemented by the Faculty of Chemical Technology of the University of Pardubice in cooperation with the University Hospital Hradec Králové and the Medical Faculty of Charles University with financial support from the European Investment and Structural Funds. The analysis of R\&D PM was performed using structured interviews with project manager, financial manager and research team leaders assessing the methods and tools of PM that are used in the project. The output of the analysis is a proposal of a suitable procedure for managing this type of project, especially in the field of less predictable activities, such as assessment of methods for evaluating the toxicity of developed materials and compiling an optimal panel of methods for such evaluation in the future. Data collection took place in the form of 6 guided online interviews with 39 questions focused on areas: assessment of theoretical knowledge and practical experience, assessment of scope, financial management and monitoring of project costs, assessment of tools and methods for managing the scope and quality of outputs, schedule management, cost management and cash flow, human resources management, risk and opportunity management, communication management, project change management and the specifics of R\&D projects.

\subsection{Results}

According to the categorization of R\&D projects (Macháčková, 2014), the NANOBIO project is a project in the field of "Matter of research" (see Figure 1). According to the division of Kuchta and Skowron (2016), NANOBIO is one of the Type 2 projects, as the defined goal is given by the Feasibility study, but the method by which these goals are to be achieved is no longer defined in detail and it is matter of implementation. These projects are generally referred to as product development projects. This classification is surprising especially because Kuchta and Skowron (2016) generally refers to R\&D projects as Type 4 due to undefined outputs and methods of their achievement, and classifies externally funded public sector projects as Type 1. This is also due to the nature of the NANOBIO project, as it is not a classic $R \& D$ project, but partially extends into a project building infrastructure, which will be available after the end of the project. The Cynefin distribution (Kempermann, 2017; Puik \& Ceglarek, 2015) is ambiguous for the NANOBIO project. It is characterized by a complex domain area, where a number of changes or unplanned activities take place during the project (changes in project team, impact of COVID-19 pandemics etc.), but the output requirements do not change during implementation, which makes NANOBIO partly the second area of the complicated domain, where expert estimates can schedule. 
The analysis of parameters using structured interviews confirmed the statement of Barbosa et al. (2020), who says that in terms of the quality of outputs and scope, quantitative indicators, such as the number of scientific publications, are also used as an indicator of success in terms of success quality and scope. Expert estimates by employees who already have experience with a similar project were used to create a time schedule. In terms of cost management, the project also supports the theoretical statement of Čáslavová (2018) that externally financed projects tend to have a high risk of non-exhaustion of costs and their management plan is given by the tender documentation. Mikulskiene (2014) cites the benefits of a fixed project team structure through the benefits of shared knowledge and knowledge integration. Within the NANOBIO project, this integration of knowledge is due to interdisciplinary overlap, as it is crucial to rely on results from other fields to ensure the project outputs. For a project, the fixed project structure is given primarily by employees in management positions. Due to the size of the project, changes occurred more often among ordinary employees, but according to Mikulskienè (2014), these changes are not to the detriment, as the knowledge of individual team members is optimally used, which increases the success of the project. However, these changes must not be very frequent, as they then lead to worse results for the whole team. Čáslavová (2018) also states that risk management is often neglected in R\&D projects. This fact was only partially confirmed, as the risks for the project were elaborated in the Feasibility Study. According to Wang and Yang (2012), over time, given risks and their measures may become inadequate. The analysis shows that risk management should move from management at the moment when there is a higher level of prevention, setting responsibilities for individual risks, regular updates and monitoring of risks within the project life cycle. The key recommendation for planning $R \& D$ projects is to set the responsibility of a specific person for individual tasks, work packages within WBS, which will communicate and share what they are currently working on, what phase the individual teams are in, which would bring a qualitative shift in PM. According to Mikulskiene (2014), it is recommended to create a communication matrix with the people responsible for the given parts for optimal communication and to determine how often this communication will take place. Such a communication matrix created in the project includes more frequent, regular scientific research, administrative and joint meetings, where current results and directions are discussed and shared within all workplaces of the project. The structured interviews revealed the need for more frequent and better communication in the case of the NANOBIO project, which would help to improve clarity within the professional activities of individual partner workplaces, where their management is currently partially intertwined and a certain ambiguity in activities arises. These professional meetings seem to be the optimal frequency once a month or two, due to the fact that during these time intervals there are reportable changes in $R \& D$ and researchers are not unnecessarily delayed by frequent meetings. The need for administrative meetings between partners is also on a monthly basis. The guided interviews showed that the NANOBIO project is approximately $80 \%$ managed by traditional waterfall PM and about $20 \%$ are unplanned activities, mainly of a professional nature. Traditional PM is more aware of professional and administrative staff, and the activities planned in advance and given by the Feasibility Study are methodically managed. In the Feasibility Study, the research topic was initially proposed in a more general way, as it was not possible to determine the specific direction of development. NANOBIO is based on the development of new nanomaterials, where it was not possible to specify in advance which nanomaterials and in what form 
they will be developed, whether they will be suitable for the intended use or can be tested in the traditional way or not. According to Doležal (2021), the most suitable way for NANOBIO would be to combine the traditional and agile way of managing projects in a hybrid way in detail. With regard to financial providers, it is recommended to proceed in the traditional way in the upper general parts of WBS NANOBIO and in the case of the lower parts of WBS, especially scientific research activities, to proceed methodically in an agile way. This hybrid approach would bring a positive effect in the field of human resource planning, where according to Čáslavová (2018), especially for externally funded projects, personnel changes are the second most common cause of changes and account for $17 \%$ of all project changes. This recommendation concerns the planning of the details of all activities, when from the point of view of the burden on employees it would be more appropriate to apply the principles of agile PM and waterfall PM procedures to stick to the general parts of the WBS. Recommended activities (communication matrix, combination of traditional and agile way of managing projects in a hybrid way in detail) have been applied for partial activities and have been evaluated as successful tools, which could help to improve the project management of NANOBIO project.

\section{Conclusion and Discussion}

R\&D activities are an important parameter of competitiveness and, in terms of requirements and technologies (Hernandez-Gonzalez et al., 2014), this is an unexplored area and it is not possible to determine which of the PM approaches is generally better. Projects in this area are specific due to the high degree of uncertainty and risk (Č́slavová, 2018; Larsen, 2005), and therefore PM must be adapted accordingly. R\&D can occur in both the private and public spheres, and collaborative research is often approached. In the case of externally funded or private sector projects, the use of a waterfall approach is more appropriate, as the output of the project or technology to be achieved is known. If the output of the project or the process or technology by which the output is to be achieved is not known, agile PM is approached, or hybrid forms combining waterfall and agile PM are used (Ko et al., 2016; Doležal, 2021).

These outputs were also confirmed within the analysis of the NANOBIO research project by the method of guided interviews. In this analysis, it was found that NANOBIO is approximately $80 \%$ managed by traditional waterfall PM and about $20 \%$ are unplanned activities, mainly of a research nature. For this reason, it is recommended to train the staff of project teams not only in the field of waterfall, but also agile PM in order to achieve effective and systematic management in these activities. Within NANOBIO, it is a combination of these two approaches in detail, in the general upper part of the WBS waterfall PM method, in the lower parts of the WBS, especially in the field of scientific research activities, management using an agile PM.

For the future research it will be useful to analyze the way of project management of other R\&D projects and compare the results and verify the effect of usage of traditional, agile or combined form of project management on $\mathrm{R} \& \mathrm{D}$ projects. 


\section{Acknowledgments}

Acknowledgments: This work was supported by OP RDE project „Strengthening interdisciplinary cooperation in research of nanomaterials and their effects on living organisms“, reg. $\mathrm{n}$. CZ.02.1.01/0.0/0.0/17_048/0007421

\section{References}

Barbosa, A. P. P. L., Salerno, M. S., Brasil, V. C., \& Nascimento, P. T. (2020). Coordination Approaches to Foster Open Innovation R\&D Projects Performance. Journal of Engineering and Technology Management, 58, 101603. https://doi.org/10.1016/j.jengtecman.2020.101603

Barbosa, A. P. P. L., Salerno, M. S., Nascimento, P. T., Albala, A., Maranzato, F. P., \& Tamoschus, D. (2021). Configurations of project management practices to enhance the performance of open innovation R\&D projects. International Journal of Project Management, 39(2), 128-138. https://doi.org/10.1016/j.ijproman.2020.06.005

Buengeler, C., Situmeang, F. B. I., Van Eerde, W., \& Wijnberg, N. M. (2020). Fluidity in project management teams across projects. International Journal of Project Management, 39(3), 282-294. https://doi.org/10.1016/j.ijproman.2020.12.001

Čáslavová, H. (2018). Project management v projektech výzkumu a vývoje [Project management in R\&D projects]. Proceeding of Public policy on research, development and innovation 2018 (pp. 74-93). Plzeň: Alevia,

Doležal, J. (2021). Hybridní př́istupy - vodopád, agile nebo něco mezi? [Hybrid approaches - a waterfall, an agile or something in between?]. IPMA Czech Republic. https://rive.google.com/file/d/1nzS9lT3gt9vinv2PCWutp0hFJvJR6mGd/view

Doskočil, R., Skapa, S., \& Olsova, P. (2016). Success Evaluation Model for Project Management. E \& $M$ Ekonomie a Management, 16(4), 167-185. https://doi.org/10.15240/tul/001/2016-4-012

Elias, A. A. (2016). Analysing the stakes of stakeholders in research and development project $\begin{array}{llll}\text { management: } \quad \text { a } & \text { systems } & \text { approach. } R \& D \quad \text { Management, 46(4), }\end{array}$ https://doi.org/10.1111/radm.12122

Hernandez-Gonzalez, Y., Garcia-Moreno, C., Rodrguez-Garcia, M. A., Valencia-Garcia, R., \& GarciaSanchez, F. (2014). A semantic-based platform for R\&D project funding management. Computers in Industry, 65(5), 850-861. https://doi.org/10.1016/j.compind.2013.11.007

Iamandi, O., Sorin, P., Diana, D., \& Cenusa, A. (2014). Research, development and innovation project risk management in a furniture cluster based start-up company. International Conference on Production Research Africa, Europe and Middle East and 3rd International Conference Quality and Innovation in Engineering and Management, Cluj-Napoca, Romania

Kasap, D., Asyali, I. S., \& Elci, K. (2007). Risk management in R\&D projects. Proceedings of PICMET '07: Portland International Conference on Management of Engineering and Technology, 1-6. 2287-+. https://doi.org/10.1109/PICMET.2007.4349560

Kempermann, G. (2017). Cynefin as Reference Framework to Facilitate Insight and Decision-Making in Complex Contexts of Biomedical Research. Frontiers in Neuroscience, 11, 634. https://doi.org/10.3389/fnins.2017.00634

Ko, J. W., Choi, J. Y., Kim, J. A., Kim, S. T., \& Cho, Y. H. (2016). Research Descriptor Based Project Management Approach for R\&D Projects. Proceeding of 10th International Scientific Conference on Future Information Technology (FutureTech), Hanoi, Vietnam. 354, 177-183. https://doi.org/10.1007/978-3-662-47895-0_22

Kostalova, J., \& Tetrevova, L. (2016). Application of Project Management Methods and Tools with Respect to the Project Life Cycle and the Project Type. Proceeding of 9th International Scientific Conference Business and Management 2016, Vilnius, Lithuania. https://doi.org/10.3846/bm.2016.03

Kuchta, D., \& Skowron, D. (2016). Classification of R\&D projects and selection of R\&D project management concept. $R \& D$ Management, 46(5), 831-841. https://doi.org/10.1111/radm.12112 
Larsen, E. R. (2005). Apply project management concepts to R\&D. Chemical Engineering Progress, 101(1), 47-50

Lee, S., Cho, Y., \& Ko, M. (2020). Robust Optimization Model for R\&D Project Selection under Uncertainty in the Automobile Industry. Sustainability, 12(23), 10210. https://doi.org/10.3390/su122310210

Macháčková, E. (2014). Osedlejte si každý projekt [Saddle every project]. Computerworld, 25(19-20), $10-11$.

McGrath, J., \& Kostalova, J. (2020). Project management trends 2020+. (2020). Proceeding of Hradec Economic Days, 2.-3.4.2020, Hradec Králové, Czech Republic, 534-542. https://doi.org/10.36689/uhk/hed/2020-01-061

Mikulskienè, B. (2014). Research and Development Project Management. Mykolo Romerio universitetas, Vilnius.

Puik, E., \& Ceglarek, D. (2015). The Quality of a Design will not Exceed the Knowledge of its Designer; an Analysis Based on Axiomatic Information and the Cynefin Framework. Procedia CIRP, 34, 1924. https://doi.org/10.1016/j.procir.2015.07.040

Reulen, H. J. (2002). Basic research vs. applied research. Proceeding of Conference on Research and Publishing Neurosurgery, 83, 45-48. https://doi.org/10.1007/978-3-7091-6743-4 8

Rothwell, R. (1994). Industrial Innovation: Success, Strategy, Trends. In M. Dodson, \& R. Rothwell (Ed.), The Handbook of Industrial Innovation, Edward Elgar, Aldershot.

Roussel, P., Saad, K., \& Erikson, T. (1991). The Third Generation R\&D. Harvard Business School Press.

Schuhmacher, A., Gassmann, O., Hinder, M., \& Kuss, M. (2021). The present and future of project management in pharmaceutical R\&D. Drug Discovery Today, 26(1), 1-4. https://doi.org/10.1016/j.drudis.2020.07.020

Spalek, S. (2016). Innovative vs. innovation projects in organisations. In: E. Wszendybył Skulska (Ed.), Innowacyjność współczesnych organizacji (pp. 226-237). TNOiK, Torun.

Taraba, P., Hart, M., \& Pitrová, K. (2016). Risk Management of Projects in the Czech Republic. Polish Journal of Management Studies, 13(1), 181-191. https://doi.org/10.17512/pjms.2016.13.1.17

Ver, C. (2018). 3D VR spaces support R\&D project management. Proceeding of the 9th IEEE International Conference on Cognitive Infocommunications (CogInfoCom), Budapest, Hungary (375-378). https://doi.org/10.1109/CogInfoCom.2018.8639900

Vincente-Oliva, S., Martínez-Sánchez, A., \& Berges-Muro, L. (2015). Research and development project management best practices and absorptive capacity: Empirical evidence from Spanish firms. International Journal of Project Management, 33(8), 1704-1716. https://doi.org/10.1016/j.ijproman.2015.09.001

Wang, J., \& Yang, C. (2012). Flexibility planning for managing R\&D projects under risk. International Journal of Production Economics, 135(2), 823-831. https://doi.org/10.1016/j.ijpe.2011.10.020 